\title{
Sport specific fitness testing of elite badminton players
}

\author{
Ming-Kai Chint, Alison SK Wong†, Raymond C H So†, Oswald T Siuキ, Kurt Steininger* and \\ Diana T L Lo§
}

+Sports Science Department, Hong Kong Sports Institute, ₹Statistical Consultation Services, City Polytechnic of Hong Kong, ${ }^{*}$ Department of Sports Medicine, University of Ulm, Germany, and §Badminton Department, Hong Kong Sports Institute

\begin{abstract}
There is a scarcity of descriptive data on the performance capacity of elite badminton players, whose fitness requirements are quite specific. The purpose of this paper is to investigate the physiological response of elite badminton players in a sport-specific fitness test. Twelve Hong Kong national badminton team players performed a field test on a badminton court. Six light bulbs were connected to a programming device causing individual bulbs to light up in a given sequence. The players were instructed to react to the flashes by running towards them, and striking shuttles mounted in the vicinity of the bulbs. Exercise intensity was controlled by altering the interval between successive lightings. A low correlation $(r=0.65)$ was found between the results of the field test and the rank-order list of subjects, based on an objective on-field physiological assessment and subjective ranking. This may be explained by the requirements of other factors besides physical fitness which contribute to success in elite level badminton competition. These factors may include, for example, technical skill, mental power, and aesthetic judgements on the court. Maximum mean(s.d.) heart rate data $(187(8)$

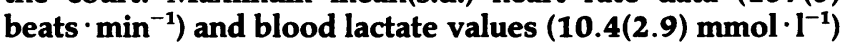
in this study showed that players were under maximal load during the field test. From the testing data, it seems reasonable to speculate that the intensity of level 3 (20 light pulses $\min ^{-1} ; 3.0 \mathrm{~s} \cdot$ pulse $\left.^{-1}\right)$ and level 4 (22 light pulses $\cdot \min ^{-1} ; 2.7 \mathrm{~s} \cdot$ pulse $^{-1}$ ) simulates the requirement of actual game energy expenditure of the Hong Kong badminton players exercising at close to their anaerobic threshold. The results also show that an estimate of fitness can be derived from measurements involving exercise closely resembling that which is specific for the sports activity in question. Improved training advice and guidance may result from such studies.

(Br J Sports Med 1995; 29 : 153-157)
\end{abstract}

Keywords: badminton; elite athletes; sports specific fitness; lactate; anaerobic threshold

It has been established that no single variable measures physical fitness, which is a composite factor varying with each sport. Badminton at the elite level requires a combination of the aerobic and anaerobic systems and the involvement of these systems depends on the nature

Address for correspondence: Ming-Kai Chin PhD, Head, Sports Science, Sports Science Department, Hong Kong Sports Institute, Shatin, Hong Kong of the rally (short or long) and the duration of the game (short set or long match). ${ }^{1}$ Apart from the demands of high levels of technical skill and mental acuity, essential requirements for badminton fitness include stamina, speed, endurance, strength, and physical agility. ${ }^{2}$ Badminton is growing in popularity and according to recent surveys there is an ever increasing number of players (approaching 200 million) worldwide. ${ }^{3}$ In the 1992 Barcelona Olympic Games, badminton was included as one of the official events for the first time. Despite the large number of badminton players internationally, research dealing with the performance capacity of elite badminton players in the English scientific literature has been scarce. ${ }^{14-7}$ Most previous physiological studies of elite badminton players originate from researchers in China. ${ }^{28-10}$

Investigations by $\mathrm{Mader}^{11}$ and Keul ${ }^{12}$ showed that the customary standardized cycle treadmill ergometry is not sufficient for an unequivocal prediction of successful performance in sport. Sport specific laboratory tests, such as rowing ergometry for rowers or cycle ergometry for cyclists, show deficiencies with respect to their capacity to forecast performance in competition. In addition, for sports involving non-rhythmic movements - such as in handball, squash, and badmintonsport specific testing is either impossible or may be performed only with the help of elaborate and expensive technical equipment. Such conclusions have prompted further research on possible means of obtaining valid estimations of the competition fitness of athletes in specific sports such as squash. ${ }^{1314}$ A specific programming device that controlled the intermittent flashes of light bulbs, designed to represent the offensive shots of an opponent in a squash game, was devised by Steininger and Wodick ${ }^{13}$ and tested in a squash court. A high correlation between subjects' rank-order and field test $(r=0.90, P<0.001)$ was found. This correlation was higher than that between subjects' rank-order and fitness level as determined by a treadmill running protocol $(r=0.52, P>0.05)$. The researchers concluded that this sport specific test provides reliable estimates of squash players' fitness levels. Since badminton is an indoor game comparable to squash, the objective of this paper was to investigate the physio- 
logical responses of elite badminton players in a modified version of Steininger and Wodick's ${ }^{13}$ sport specific fitness test.

\section{Methods}

Twelve top badminton athletes (six men and six women) served as subjects for this study. All subjects (mean(s.d.) age 24.4(2)years) were scholarship athletes of the Hong Kong Sports Institute (HKSI) and national team members who had represented Hong Kong in several international tournaments. Four of the male players were team event bronze medallists at the 1990 Commonwealth Games. One mixed doubles pair and one female doubles pair were in the top 10 in the world rankings in 1993. As a group, they had accumulated a mean of 7 years' playing experience. Athletes regularly underwent training, 4 hours per day, 6 days a week, for 11 months of the year. An average of 50 matches was played by each athlete during the season. Informed consent was obtained from all subjects before the testing process. Male and female data were pooled in accordance with the rank list (for explanation see below) which listed the badminton players regardless of sex.

The field test was executed in one half of a badminton court. Six light bulbs were individually mounted on posts, with one shuttle at the top end of each post. The lights were connected to a programming device ${ }^{13}$ located outside the court. The first pair of lights (LI and R1) was located near the forecourt, the second pair (L2 and R2) at midcourt, and the third pair (L3 and R3) at the rear. The layout of the test is illustrated in Figure 1. Different fixed programmes (switch-in sequences of light flashes) were selected for each of the exercise intensities. In addition, the switching frequency could

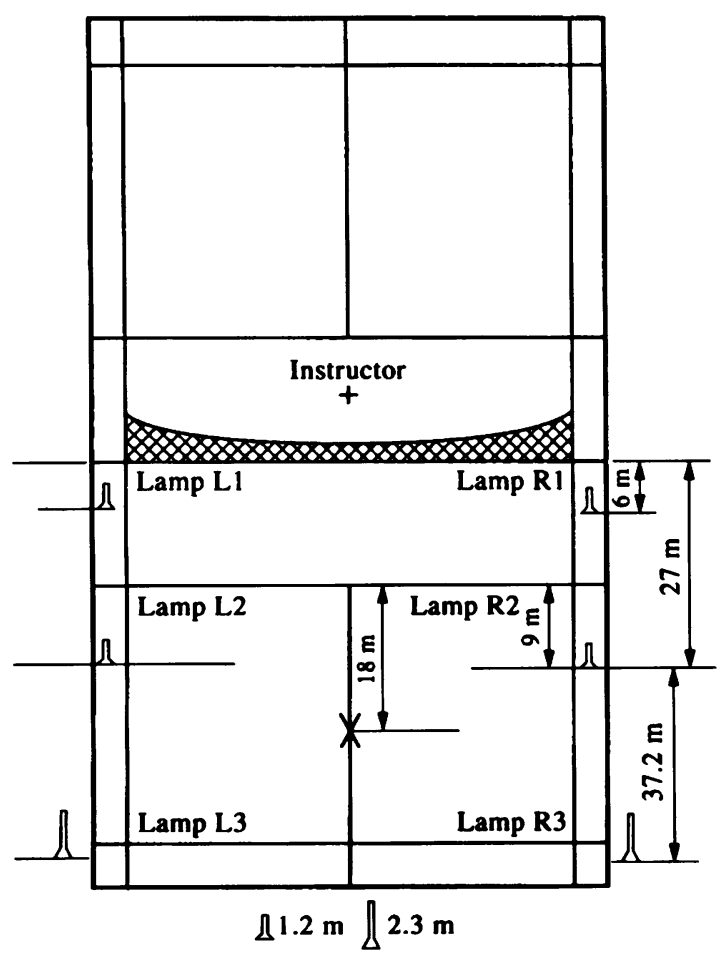

Figure 1. Badminton field test be altered in a stepwise manner. The subjects were instructed to run from a central point (point $X$ ) towards each shuttle as soon as the corresponding bulb was lit and to strike the shuttle in a technically appropriate manner. For the forecourt and midcourt light flashes, subjects performed a front and side lunge. For the rear court flashes, it was necessary to imitate a backward jump smash and land between the court lines, and then return to the central point. The test consisted of successive 3 min periods of exercise. At the beginning 16 light pulses $\cdot \mathrm{min}^{-1}$ were delivered, resulting in a total of 48 pulses (dashes) at intensity level I. The intensity was then increased by six pulses (dashes) per level until subjective exhaustion was reached, that is, until a lamp was lit before the preceding one was touched by the subject. Maximum intensity could be increased to 26 light pulses $\cdot \mathrm{min}^{-1}$ which occurred at level 6 . When it is necessary, the subjects will then continue in this same maximal intensity for another two levels, that is 7 and 8, to reach subjective exhaustion.

To determine lactate concentration, blood was drawn from the finger tip of the non-dominant arm (which was defined as the arm not holding the racquet), during a $45 \mathrm{~s}$ rest interval interposed between each level of exercise, and at 1 and $3 \mathrm{~min}$ after cessation of activity. Blood lactate concentrations were determined using an Analox GM7 lactate analyser (Analox Instruments) and the value of $4 \mathrm{mmol} \cdot$ litre $^{-1}$ was taken as the anaerobic threshold. Heart rate readings were recorded with the Sport Tester (TM) $\mathrm{PE}_{4000}$ heart rate monitor (Polar Electro OY) throughout the whole testing period, and at 1,3 , and 5 min following the termination of activity.

A rank order was established for the athletes by the national coach, based on competitive results during the previous season and on subjective estimation of current badminton fitness obtained from match play. This rank order list was made without knowledge of the results of the field tests. The rank order list was independent of age and sex. From this list, fitness coefficients were derived which served as a basis for comparison with the results of field test. Fitness estimation factors in the field test consist of three variables: circulation recovery, maximum performance, and threshold performance. The ranking of circulation recovery was calculated by subtracting the heart rate $5 \mathrm{~min}$ after load, from the maximum heart rate of the last stage. The subject with the largest differential was considered to have the best circulation recovery. Maximum performance was ranked according to the number of levels achieved. For subjects achieving the highest possible level, that is stage 8, lowest lactate levels determined maximum performance. Threshold performance was ranked according to the number of light pulses $\cdot \mathrm{min}^{-1}$ at 4 $\mathrm{mmol} \cdot$ litre $^{-1}$ lactate level. The highest rating was assigned to the subject recording the largest number of light pulses at this blood lactate concentration. The relationship between these coefficients (match vs. field test) was established by linear correlation. Mean(s.d.) values were calculated. 


\section{Results}

The results obtained in the field test are presented in Table 1. The maximum (mean(s.d.)) heart rate data and blood lactate values recorded during the field test were $187(8)$ beats $\cdot \mathrm{min}^{-1}$ and $10.4(2.9) \mathrm{mmol} \cdot$ litre $^{-1}$ respectively. Mean(s.d.) values for performance and heart rate at the AT for the field test was 21 (3) light pulses $\cdot \mathrm{min}^{-1}$ and $170(9)$ beats $\cdot \mathrm{min}^{-1}$ respectively. Fitness coefficients calculated on the basis of these data are presented in Table 2. Fitness coefficients were compared with the corresponding coefficients derived from the rank order list. There was a low correlation between the rank order and field test $(r=0.65 ; P>0.05 ;$ Figure 2$)$. Heart rate and blood lactate responses at each level of exercise intensity are presented in Figures 3 and 4 . Three of the subjects who were members of the national team in three consecutive years (1990-92) had repeated the field test annually and the results are presented in Figure 5. All three subjects had improved to reach the maximum level from level 5 ( 24 lights pulses $\cdot \mathrm{min}^{-1}$; $2.5 \mathrm{~s} \cdot \mathrm{pulse}^{-1}$ ) to level 8 ( 26 lights pulses $\cdot \mathrm{min}^{-1}$; $2.3 \mathrm{~s} \cdot$ pulse $\left.^{-1}\right)$ during this three year period $(9 \mathrm{~min}$ longer in testing duration).

\section{Discussion}

Badminton requires the performance of work in the nature of sprints, stops and starts, jumps, leaps, lunges, rapid changes of direction, twists and turns and a variety of strokes. ${ }^{1}$ To become an elite badminton athlete, the fitness requirement is quite specific. Over the past few years, badminton as played in Asia has focused a greater emphasis on fitness, especially in terms of speed and recovery powers. ${ }^{15}$ This field test was devised in a way such that the subjects' activity was very similar to that during an actual badminton game.

The low correlation between the field test data and the rank order list $(r=0.65)$ may indicate that there are other important factors besides physical fitness, which are essential for success in top level badminton competitions. These may include factors such as technical and perceptual skill, mental power, tactics and aesthetic judgements in the court. ${ }^{1216}$

A three game match of badminton can last from $40 \mathrm{~min}$ to over $\mathrm{I} \mathrm{h}$ in an international competition. It consists of short bursts of activity followed by short rest periods. It has been estimated that $60-70 \%$ of the energy during play is derived aerobically and $30 \%$ anaerobically. ${ }^{2}$ Maximum (mean(s.d.)) oxygen uptake $\left(\mathrm{V}^{2 \text { max }}\right)$ values for top Chinese male and female players, including Thomas Cup and All-England Champions, were recorded as 63.4(4.0) and $53.3(3.6) \mathrm{ml} \cdot \mathrm{kg}^{-1} \cdot \mathrm{min}^{-1}$ respectively. ${ }^{7}$ Reilly ${ }^{5}$ reported a value of $68.0 \mathrm{ml} \cdot \mathrm{kg}^{-1} \cdot \mathrm{min}^{-1}$ for a top British player. Elite badminton athletes' muscle fibres are large and have high capillary density. ${ }^{4}$ For the vastus lateralis muscle, a high percentage of slow twitch fibres has been recorded in elite male players [63\% (50-72\%)] and female players $[56 \%(42-63 \%)]{ }^{9}$ Thus there is a tendency towards the muscle fibre distribution of endurance athletes. Investigators ${ }^{817}$ recorded very high working heart rates $\left(170-180\right.$ beats $\left.\cdot \mathrm{min}^{-1}\right)$ for the duration of single matches during important international badminton competitions and found that the heart rate rarely drops during the average $10 \mathrm{~s}$ rest periods. These findings are in agreement with another energy expenditure study ${ }^{1}$ conducted on a badminton court, which reported that only occasionally did subjects' heart rate drop below 160 beats $\cdot \mathrm{min}^{-1}$. For highly skilled badminton athletes, Docherty ${ }^{18}$ has observed that mean heart rate during play represents $80 \%$ of the predicted maximum heart rate and is higher than that of tennis and squash athletes of similar skill level. It is suggested that this may be due to light muscle group work and the light racquet involved in badminton. ${ }^{5}$ The maximum (mean(s.d.)) heart rate data $\left(187(8)\right.$ beats $\left.\cdot \mathrm{min}^{-1}\right)$ and blood lactate values $\left(10.4(2.9) \mathrm{mmol} \cdot\right.$ litre $\left.^{-1}\right)$ in this study showed that the subjects were under maximal load during a field test, as a lactate concentration of $12 \mathrm{mmol} \cdot$ litre $^{-1}$ or more has been considered as a value indicating exhaustion. ${ }^{11}$ The high blood lactate values in this field test may be explained by the intense muscle use with a high motivation for reaching the maximal levels. A fast recovery in exercise heart rate was found, dropping a mean value of 72 beats $\cdot \min ^{-1}$ in the $5 \mathrm{~min}$ following termination of exercise. This quick recovery from strenuous exercise may be due to the regular interval training (specific training involving intermittent efforts interspersed with short rests) undertaken by the subjects as part of their overall badminton training programme, and the similar sporting environment.

It is interesting to note that mean(s.d.) values for performance and heart rate at the anaerobic threshold for the field test were 21(3) light pulses $\cdot \mathrm{min}^{-1}$ and $170(9)$ beats $\cdot \mathrm{min}^{-1}$ respectively (Table 1 ). The mean(s.d.) heart rate values $\left(167(12)\right.$ beats $\cdot \mathrm{min}^{-1} ; 176(10)$ beats $\left.\cdot \mathrm{min}^{-1}\right)$ and mean(s.d.) blood lactate values $(4.3(2.5)$ $\mathrm{mmol} \cdot$ litre $^{-1} ; 6.3(3.2) \mathrm{mmol} \cdot$ litre $\left.^{-1}\right)$ were recorded in level 3 and 4 ( 20 and 22 light pulses $\cdot \mathrm{min}^{-1}$ ) respectively (Figures 3 and 4). In previous studies mean heart rate ranged from $160-180$ beats $\cdot \mathrm{min}^{-1(1517-19)}$ and low levels of blood lactate (average between 3.0 and 5.7 $\mathrm{mmol} \cdot$ litre $^{-1}$ ) were found during badminton games. ${ }^{245} 19$ Mean(s.d.) blood lactate values of $3.99(0.85)$ and $4.18(1.01) \mathrm{mmol} \cdot$ litre $^{-1}$ respectively were obtained from 107 elite male and 103 elite female Chinese badminton athletes during an important provincial invitation tournament in 1992. ${ }^{2}$ Therefore it may be reasonable to suggest that a highly competitive badminton match may require Hong Kong badminton players to exercise at close to their anaerobic threshold which occurred between level 3 and 4 during the field test. Moreover, several studies have suggested that exercise intensity which elicits a lactate concentration of $4 \mathrm{mmol} \cdot$ litre $^{-1}$ induces an optimal qualitative stimulus for adaption to endurance training. ${ }^{20-23}$ Therefore, it is suggested that badminton players can include level 3 and 4 with a duration of $30 \mathrm{~min}$ or $45 \mathrm{~min}$ as one of the means of fitness conditioning together with shadow badminton or playing to continuous high pressure feeding from the coach near the competition period.

It has been reported that coaches in sports such as 
Table 1. Results of the field test for individual players

\begin{tabular}{|c|c|c|c|c|c|c|c|}
\hline \multirow[b]{2}{*}{ Subject } & \multirow[b]{2}{*}{$\begin{array}{c}H R_{\max } \\
\left.\text { (beats } \cdot \min ^{-1}\right)\end{array}$} & \multirow[b]{2}{*}{$\begin{array}{l}\text { HR } 5 \text { min after } \\
\text { load end }\end{array}$} & \multirow[b]{2}{*}{$\begin{array}{c}L A_{\max } \\
\left(m m o l \cdot \text { litre }^{-1}\right)\end{array}$} & \multicolumn{2}{|c|}{ Maximum performance } & \multirow{2}{*}{$\begin{array}{l}\text { Performance at } \\
\text { the anaerobic } \\
\text { threshold (light } \\
\text { pulses } \cdot \min ^{-1} \text { ) }\end{array}$} & \multirow{2}{*}{$\begin{array}{l}\text { HR at the } \\
\text { anaerobic } \\
\text { threshold } \\
\left(\text { beats } \cdot \mathrm{min}^{-1}\right)\end{array}$} \\
\hline & & & & $\begin{array}{l}\text { Last load } \\
\text { step }\end{array}$ & Time $(\min )$ & & \\
\hline A & 189 & 110 & 9.8 & 8 & 3.0 & 23 & 174 \\
\hline B & 175 & 102 & 7.0 & 8 & 3.0 & 22 & 153 \\
\hline $\mathrm{C}$ & 190 & 112 & 6.0 & 6 & 3.0 & 24 & 184 \\
\hline D & 199 & 131 & 12.4 & 8 & 3.0 & 20 & 172 \\
\hline$E$ & 186 & 116 & 12.3 & 8 & 1.9 & 22 & 170 \\
\hline $\mathrm{F}$ & 197 & 136 & 14.8 & 8 & 3.0 & 21 & 174 \\
\hline G & 173 & 110 & 6.8 & 8 & 3.0 & 23 & 165 \\
\hline $\mathrm{H}$ & 182 & 113 & 14.4 & 5 & 2.0 & 16 & 159 \\
\hline 1 & 182 & 100 & 9.4 & 5 & 2.2 & 19 & 172 \\
\hline J & 190 & 108 & 10.0 & 7 & 2.0 & 17 & 161 \\
\hline K & 193 & 122 & 9.8 & 6 & 3.0 & 20 & 182 \\
\hline L & 183 & 114 & 11.9 & 4 & 1.2 & 16 & 172 \\
\hline $\operatorname{Mean}($ s.d.)* & $187(8)$ & $115(11)$ & $10.4(2.9)$ & - & - & $20.3(2.8)$ & $170(9)$ \\
\hline
\end{tabular}

$H R=$ heart rate; $L A=$ blood lactate

${ }^{*} n=12$

Table 2. Fitness estimation factors calculated on the basis of data presented in Table 1

\begin{tabular}{ccccc}
\hline $\begin{array}{c}\text { Test } \\
\text { person }\end{array}$ & $\begin{array}{c}\text { Circulation } \\
\text { recovery }\end{array}$ & $\begin{array}{c}\text { Max } \\
\text { performance }\end{array}$ & $\begin{array}{c}\text { Threshold } \\
\text { performance }\end{array}$ & $\begin{array}{c}\text { Estimation } \\
\text { factors } \\
\bar{x}(\mathrm{n}=3)\end{array}$ \\
\hline A & 3 & 3 & 2 & 2.7 \\
B & 5 & 2 & 5 & 4.0 \\
C & 4 & 8 & 1 & 4.3 \\
D & 9 & 5 & 7 & 7.0 \\
E & 7 & 4 & 4 & 5.0 \\
F & 11 & 6 & 6 & 7.7 \\
G & 12 & 1 & 3 & 5.3 \\
H & 10 & 11 & 11 & 10.7 \\
I & 1 & 10 & 9 & 6.7 \\
J & 2 & 7 & 10 & 6.3 \\
K & 6 & 9 & 8 & 7.7 \\
L & 8 & 12 & 12 & 10.7 \\
\hline
\end{tabular}

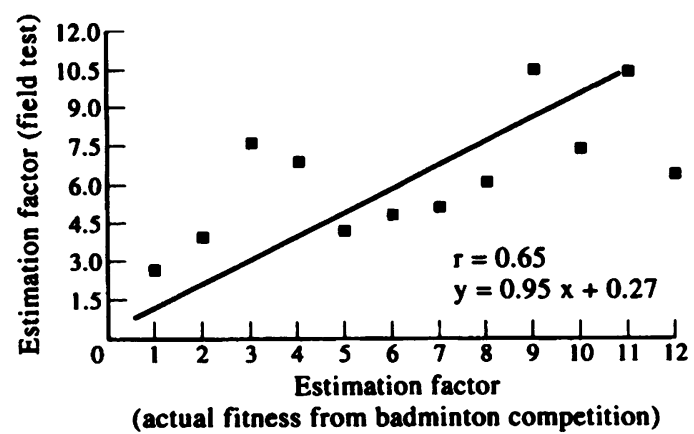

Figure 2. Correlation between rank orders field test and actual fitness

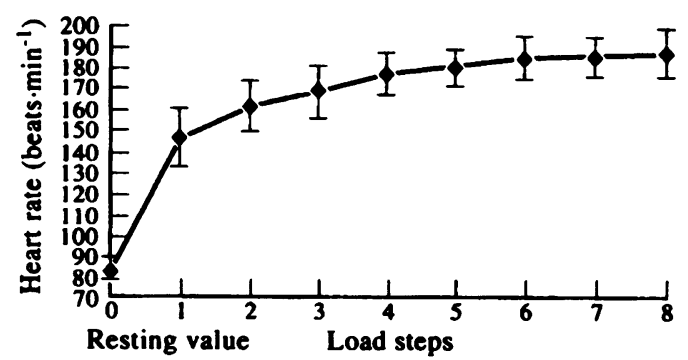

Figure 3. Heart rate values in field test $(n=12$; mean(s.d.))

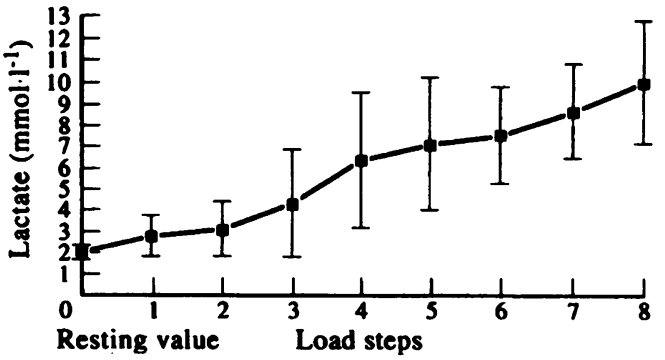

Figure 4. Blood lactate values in field test $(n=12$; mean(s.d.))

track, swimming, and rowing are routinely monitoring lactate levels after training intervals. ${ }^{24-26}$ Urhausen $e^{2} a^{27}$ have suggested that individual anaerobic thresholds could be a relevant instrument in training practice in order to aim at defined lactate ranges. It is tempting to speculate that blood lactate may also be a good indicator for on-court conditioning in badminton.

Three of the subjects who were members of the national team in three consecutive years (1990-92) have repeated the field test annually and the results are presented in Figure 5. Although this repeated measurement is limited by a relatively small number of subjects, certain trends are evident. All three subjects had improved to reach the maximal level from level 5 to 8 during this three year period $(9 \mathrm{~min}$ longer in testing duration). Considering the high exercise intensity (26 light pulses $\cdot \min ^{-1} ; 2.3 \mathrm{~s} \cdot$ pulse $\left.^{-1}\right)$ at those levels, that is a considerable improvement in endurance fitness. Heart rate and lactate levels at each exercise level of the field test are relatively lower in comparison to each subsequent year. It is reasonable to suggest that there is a training induced improvement in endurance which may be due to increased capillarization, ${ }^{28}$ enzyme activities, ${ }^{29}$ peripheral capacity of the musculature to utilize oxygen ${ }^{30}$ and lactate clearance ${ }^{31}$ associated with training.

In conclusion, we believe that this field test allows the calculation of reasonable estimates of badminton athletes' fitness levels and may also be included as one of the means of on-court fitness conditioning. The regular, repeated physiological monitoring with on-field stimu- 


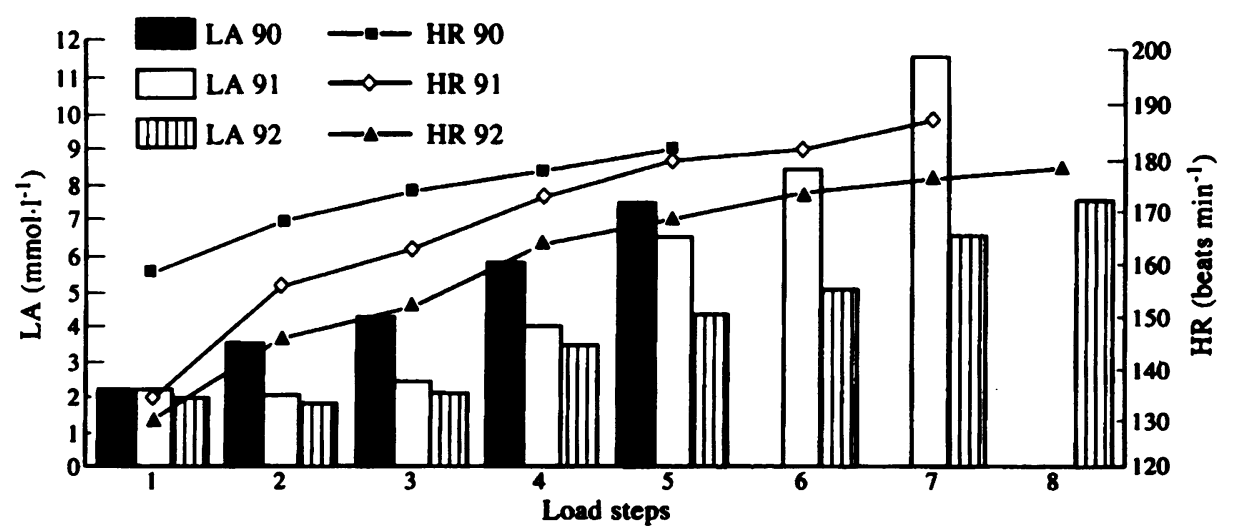

Figure 5. Mean heart rate and blood lactate (LA) values during field test in 1990-92 $(n=3)$

lation of badminton stroke moves is welcomed by the Hong Kong national coaches and may give a good indication of improvement or otherwise in training of each individual athlete.

\section{Acknowledgements}

This study was supported in part by a research grant from the Hong Kong Sports Development Board. The authors are grateful to the Hong Kong badminton athletes who participated in the study. They also express their appreciation to Miss Trisha Leahy for her valuable suggestions regarding this manuscript; Miss Yvonne Yuan for her technical assistance; and Miss Queenie Tam for her excellent clerical support.

\section{References}

1 Dewney J, Brodie D. Get fit for badminton. London: Pelham Books, 1980.

2 Lei RR, Deng SX, Lu LF. Study on the physiological function, physical quality and mental characteristics of the Chinese badminton players. Chin Sports Sci Technol 1993; 29: 28-38.

3 Eddy D. Are you coming to the party? Badminton 1993; 3(2):5-6.

4 Mikkelsen F. Physical demands and muscle adaptation in elite badminton players. In: Terauds J, ed: Science in racquet sports. Del Mar, CA: Academic Publishers, 1979: 55-67.

5 Reilly T. Racquet sports. In: Reilly T, Secher N, Snell P, William C eds. Physiology of sports. London: E \& FN Spon, 1990, 350-54.

6 Miao SK. Effect of badminton competition and training in top players' heart rate, blood lactate and oxygen debt. Acta Physiol Sinica 1980; 32: 351-56.

7 Miao SK, Wang SW. The measurement of aerobic, anaerobic capacity and extremital strength of Chinese top badminton players. In: Abstracts New Horizons of Human Movement, Vol. III SOSCOC, Seoul 1988, 252.

8 Miao SK, Wang SW, Lu SZ. The relationship of physiological characteristics and training of badminton players during competition. Chin Sports Sci Technol 1979; 1: 28-35.

9 Miao SK. Physiological foundation of badminton players during competition. Chin Sports Sci Technol 1986; 8: 1-6.

10 Yo CY, Cen HW, Wang SW. Physiological profiles of Chinese National badminton team of Barcelona Olympic Games. Zheijiang Sports Sci Technol 1993; 15: 1-7.

11 Mader A, Liesen H, Heck H, Philippe H, Schuerch PM, Hallmann $W$. Zur Beurteilung der sportartspezifischen Leistungs fahigkeit im Labour. Sportarst und Sportmedizin 1976; $27: 80-8$.

12 Keul J, Dickhut H, Berg A, Lehmann M, Huber G. Allgemeine and sport artspezifische Leistungsdiagnostik im Hochleistungsbereich. Leistungssport 1981; 11 : 382-90.
13 Steininger K, Wodick RE. Sports-specific fitness testing in squash Br J Sports Med 1987; 21 : 23-6.

14 Chin MK, Steininger K, So CH, Clark CR, Wong SK. Physiologica profile and sports-specific fitness of Asian elite squash players. Br J Sports Med 1995; 29 : 158-164.

15 Whetnall P, Leahy T. Badminton. London: BT Batsford, 1987.

16 Roper P. Badminton-the skills of the game. Salisbury: Crowood Press, 1985.

17 Astrand PO, Rodahl K. Textbook of work physiology-physiological bases of exercise, 3rd ed. New York: McGraw-Hill, 1986.

18 Docherty D. A comparison of heart rate responses in racquet games. Br J Sports Med 1982; 16: 86-100.

19 Togashi K, Ikarugi H, Nakatani T, Yoshizato H, Soya H. Heart rate and blood lactate response during badminton game (abstract). Asian Sports Sciences Congress: The Most Advanced Technology in Sports (25-27 September), Hiroshima, 1994; 142.

20 Hollmann W, Rost R, Leisen $H$, et al. Assessment of different forms of physical activity with respect to preventive and rehabilitative cardiology. Int J Sports Med 1981; 2: 67-80.

21 Mader $A$. The contribution of physiology to the science of coaching. In: Zimri U, ed. The art and science of coaching. Netanya: The Wingate Institute Press, 1980; 10-29.

22 Sjodin B, Jacobs I, Svedenhag J. Changes in onset of blood lactate accumulation (OBLA) and muscle enzymes after training at OBLA. Eur J Appl Physiol 1982; 49: 45-7.

23 Yoshida T, Suda Y, Takeuchi N. Endurance training regimen based on arterial blood lactate: effects on anaerobic threshold. Eur J Appl Physiol 1982; 49 : 223-30.

24 Foehrenbach R, Mader A, Hollmann W. Determination of endurance capacity and prediction of exercise intensities for training and competition in marathon runners. Int J Sports Med $1987 ; 8$ : 11-18.

25 Hartmann U, Mader A, Hollmann W. Heart rate and lactate training during endurance training program in rowing and its relation to the duration of exercise by top elite rowers. FISA Coach 1990; 1: 1-4.

26 Pyne D, Telford D. Classification of swimming training sessions by blood lactate and heart rate responses. Excel 1988; 5 : 9-12.

27 Urhausen A, Coen B, Weiler B, Kindermann W. Individual anaerobic threshold and maximum lactate steady state. Int J Sports Med 1993; 14 : 134-39.

28 Jacobs J, Schele R, Sjodin B. A single blood lactate determination as an indicator or cycle ergometer endurance capacity. Eur J Appl Physiol 1983; 50: 355-64.

29 Klausen K, Anderson LB, Pelle I. Adaptative changes in work capacity, skeletal-muscle, capillarization and enzyme levels during training and detraining. Acta Physiol Scand 1981; 113: 9-16.

30 Klausen K, Secher NH, Clausen JP, Hartling O, Trap-Jensen J. Central and regional circulatory adaptations to one-leg training. J Appl Physiol 1982; 52 : 976.

31 Donovan CM, Brooks GA. Endurance training affects lactate clearance, not lactate production. Am J Physiol 1983; 244: E83-E92. 